\title{
Paramyxoviruses respiratory syncytial virus, parainfluenza virus, and human metapneumovirus infection in pediatric hospitalized patients and climate correlation in a subtropical region of southern China: a 7-year survey
}

\author{
Wen-Kuan Liu ${ }^{1} \cdot$ De-Hui Chen ${ }^{2} \cdot$ Wei-Ping Tan $^{3} \cdot$ Shu-Yan Qiu ${ }^{1} \cdot$ Duo Xu ${ }^{1} \cdot$ Li Zhang $^{1} \cdot$ Shu-Jun Gu$^{2} \cdot$ Rong Zhou $^{1}$. \\ Qian Liu ${ }^{4,5}$
}

Received: 13 June 2019 / Accepted: 26 August 2019/Published online: 5 September 2019

(C) The Author(s) 2019

\begin{abstract}
To investigate the features of paramyxovirus respiratory syncytial virus (RSV), parainfluenza virus (PIV), and human metapneumovirus (HMPV) infection and determine the effect of meteorological conditions in Guangzhou, a subtropical region of southern China. We collected 11,398 respiratory samples from hospitalized pediatric patients with acute respiratory illness between July 2009 and June 2016 in Guangzhou. The samples were tested simultaneously for 18 respiratory pathogens using real-time PCR. Local meteorological data were also collected for correlation analysis. Of 11,398 patients tested, 5606 (49.2\%) patients tested positive for one or more pathogens; RSV, PIV, and HMPV were the first, sixth, and ninth most frequently detected pathogens, in 1690 (14.8\%), 502 (4.4\%), and 321 (2.8\%) patients, respectively. A total 17.9\% (4605/5606) of patients with positive results had coinfection with other pathogens. Significant differences were found in the prevalence of RSV, PIV, and HMPV among all age groups $(p<0.001)$. RSV and HMPV had similar seasonal patterns, with two prevalence peaks every year. PIV appeared alternatively with RSV and HMPV. Multiple linear regression models were established for RSV, PIV, and HMPV prevalence and meteorological factors $(p<0.05)$. RSV and PIV incidence was negatively correlated with monthly mean relative humidity; RSV and HMPV incidence was negatively correlated with sunshine duration; PIV incidence was positively correlated with mean temperature. We described the features of paramyxovirus infection in a subtropical region of China and highlighted the correlation with meteorological factors. These findings will assist public health authorities and clinicians in improving strategies for controlling paramyxovirus infection.
\end{abstract}

Keywords Respiratory syncytial virus · Parainfluenza virus · Human metapneumovirus · Acute respiratory illness · Epidemiology $\cdot$ Meteorological conditions

Rong Zhou

zhourong@gird.cn

Qian Liu

qianliu_ln@163.com

Wen-Kuan Liu

ahlwk2000-2004@163.com

De-Hui Chen

cdh84@126.com

Wei-Ping Tan

13556196566@163.com

\author{
Shu-Yan Qiu \\ 664380820@qq.com \\ Duo Xu \\ 264027412@qq.com \\ Li Zhang \\ 1069644029@qq.com \\ Shu-Jun Gu \\ 387849060@qq.com
}

Extended author information available on the last page of the article 


\section{Introduction}

Respiratory syncytial virus (RSV), parainfluenza virus (PIV), and human metapneumovirus (HMPV) are enveloped, nonsegmented, negative-sense, singlestranded RNA viruses belonging to the Paramyxoviridae family. These viruses are a significant cause of morbidity and mortality globally, especially among children in developing countries [1-7]. RSV is the most important pathogenic infection of childhood worldwide, causing a variety of manifestations from mild upper respiratory tract illnesses or otitis media to severe and potentially lifethreatening lower respiratory tract illnesses $[6,8-11]$. Four PIV types (PIV1-4) have been identified [12, 13]. PIV1 and PIV2 are best known as the cause of croup whereas PIV3 is a common cause of bronchiolitis and pneumonia [7]. PIV4 infection has low prevalence [13]. HMPV was first discovered in patients with acute respiratory illness (ARI) in 2001 [14]. Since then, HMPV has been associated with ARI in children as well as elderly and immunocompromised adults [15-17]. RSV, PIV, and HMPV are also important causes of nosocomial infection, which might be life-threatening in certain individuals, such as transplant or immunocompromised patients [18-25]. Until now, no effective vaccine for RSV has been available. The RSV-specific monoclonal antibody palivizumab has been advocated for use as prophylaxis in high-risk patients against RSV infection [26-28]. However, there is no available vaccine or specific antiviral treatment for PIV and HMPV infection. Consequently, it is imperative to conduct further research, especially in low- and middle-income countries, to understand the epidemiological features of these pathogens in different areas and populations.

In general, the prevalence of viruses can vary because of factors such as geographical location, climatic conditions, population, and social activity [29]. Guangzhou, which is located on the subtropical coast of China, has a maritime subtropical monsoon climate. Guangzhou is China's first gateway hub to Southeast Asia and Oceania. The city is densely populated and frequent exchanges of domestic and international personnel and materials take place in the area. Guangzhou has been a hotbed of activity for various respiratory pathogens. Investigation of respiratory pathogen epidemics in the region is critical.

In this study, we analyzed paramyxovirus infection among children hospitalized with ARI over a 7-year period in Guangzhou, and we collected local meteorological data for climate correlation analysis. These data will be helpful for the prevention and control of these viruses.

\section{Materials and methods}

\section{Study design and respiratory samples, and meteorological data collection}

We performed a cross-sectional study in three tertiary hospitals between July 2009 and June 2016 in Guangzhou, southern China. Pediatric patients $(n=11,398)$ hospitalized with ARI were enrolled in this study. The detail inclusion criteria were pediatric patients $(\leq 14$ years old $)$ who presented with at least two of the following symptoms: cough, pharyngeal discomfort, nasal obstruction, rhinitis, or dyspnea during the previous week. Patients who were diagnosed with pneumonia by chest radiography during the previous week were also included in the study, even if they did not show the clinical features described above. Some patients who had been cured and discharged some time ago but were then readmitted because of a new episode of ARI were included as new cases if met the recruitment criteria; otherwise, they were excluded. Chest radiography was conducted according to the clinical situation of the patient. Respiratory samples, including throat swab, sputum, or bronchoalveolar lavage fluid, were collected from the enrolled patients for routine screening of respiratory viruses, Mycoplasma pneumoniae (MP), and Chlamydophila pneumoniae (CP), according to established clinical protocols [13]. The samples were refrigerated at $2-8{ }^{\circ} \mathrm{C}$ in viral transport medium, transported on ice, and analyzed immediately or stored at $-80^{\circ} \mathrm{C}$ before analysis, as described previously [30].

We also collected meteorological data of Guangzhou (longitude $\mathrm{E} 112^{\circ} 57^{\prime}$ to $\mathrm{E} 114^{\circ} 3^{\prime}$, latitude $\mathrm{N} 22^{\circ} 26^{\prime}$ to $\mathrm{N} 23^{\circ} 56^{\prime}$ ), including the monthly mean temperature $\left({ }^{\circ} \mathrm{C}\right)$, mean relative humidity $(\%)$, rainfall $(\mathrm{mm})$, sunshine duration $(\mathrm{h})$, mean wind speed $(\mathrm{m} / \mathrm{s})$, mean air pressure $(\mathrm{hPa})$, and mean vapor pressure (hPa) from the China Meteorological Administration between July 2009 and June 2016.

\section{Real-time PCR for detection of RSV, PIV, HMPV, and common respiratory pathogens}

TaqMan real-time PCR was conducted to detect RSV, PIV14, HMPV, and other 12 common respiratory pathogens, including influenza A virus (infA), influenza B virus (infB), human rhinovirus (HRV), enterovirus (EV), four types of coronaviruses (HCoV-229E, -OC43, -NL63, and -HKU1), adenovirus (ADV), human bocavirus ( $\mathrm{HBoV}), \mathrm{MP}$, and $\mathrm{CP}$, as previously reported [13]. Briefly, real-time-PCR and RNA/ DNA extraction kits were purchased from Guangzhou HuYanSuo Medical Technology Co., Ltd. RNA/DNA was extracted from $200-\mu \mathrm{L}$ samples, according to the manufacturer's protocol. The cycling conditions were $48{ }^{\circ} \mathrm{C}$ for $10 \mathrm{~min}, 94{ }^{\circ} \mathrm{C}$ for $2 \mathrm{~min}$, and then 40 cycles of $94{ }^{\circ} \mathrm{C}$ for 
$10 \mathrm{~s}$ and $55^{\circ} \mathrm{C}$ for $35 \mathrm{~s}$. The amplified products were detected using the Applied Biosystems 7500 Real-Time PCR System (Life Technologies, Singapore). The sensitivity of the detection kits was 500 copies $/ \mathrm{mL}$ and 1000 copies $/ \mathrm{mL}$ for the target DNA and RNA, respectively.

\section{Statistical analysis}

Statistical analysis was performed using SPSS 19.0 (SPSS Inc., Chicago, IL, USA). Numerical data were presented as mean \pm standard deviation for continuous variables of meteorological data, percentage for normal discrete variables, or median (interquartile range, IQR) for age distribution. Categorical data were compared with the chi-squared test. Multiple linear regression analysis was performed with RSV, PIV, and HMPV prevalence as dependent variables and meteorological factors as independent variables. Linear correlations of meteorological independent variables were analyzed to exclude any effect on the final multiple linear regression analysis. The independent variable mean temperature drop 1 month (mean temperature in the preceding month) was also included as an independent variable in the multiple linear regression analysis because of its delay effect. A $p$ value $<0.05$ (two-tailed) was considered statistically significant.

\section{Results}

\section{Patients and paramyxovirus infection}

Over a 7-year period, a total of 11,398 patients were enrolled in the study and screened for RSV, PIV, HMPV, and 12 respiratory pathogens (Table 1). The median age of patients was 1.8 years (IQR, $0.8-3.8$ ), and the sex ratio was 1.8:1. Of the 11,398 patients tested, $5606(49.2 \%)$ had positive results for one or more of the pathogens of interest, and $17.9 \%$ (1001/5606) of positive patients were found to have coinfection with two or more pathogens. The median age of pathogen-positive patients was 1.5 years (IQR, 0.7-3.0), and positive patients had a higher sex ratio (1.9:1) than patients who tested negative for all pathogens $(1.7: 1)(p=0.002)$.

RSV, PIV, and HMPV were the first, sixth, and ninth most frequently detected pathogens, with prevalence of $14.8 \%$ (1690/11398), 4.4\% (502/11398), and 2.8\% (321/11398), respectively (Fig. 1, Table 1). The median age of patients who tested positive for these paramyxoviruses was 1.3 years (IQR, $0.4-1.8$ ), 1.7 years (IQR, 0.6-2.5), and 2.1 years (IQR, 0.83.0 ), respectively. The sex ratio of patients positive for these three viruses was 2.4:1, 2.4:1, and 2:1, respectively.
Age distribution of patients with RSV, PIV, or HMPV infection

Patients were divided into seven age groups to clarify the age distributions for these three paramyxoviruses, as follows: age 0-3 months, 4-6 months, 7-12 months, $1-2$ years, 3-5 years, 6-10 years, and 11-14 years. Significant differences were found in the prevalence of RSV, PIV, and HMPV among all age groups $(p<0.001)$, and prevalence declined with age for RSV. Peak prevalence was found in patients aged 4-6 months (7.7\%, 83/1084) for PIV; high HMPV prevalence was found in patients 4 months to 5 years old, $2.9 \%(35 / 1203)$ to $3.4 \%$ (124/3601) (Fig. 2).

\section{Seasonal distribution of RSV, PIV, and HMPV}

Overall, in the 7-year period study, RSV and HMPV had similar seasonal patterns as well as two clear prevalence peaks each year. The larger peak of RSV and HMPV prevalence appeared during the change of season from winter to spring, mainly occurring in February to April every year. The smaller peak was mainly observed in August to October each year, during the shift from summer to autumn (Fig. 3). PIV prevalence increased as autumn turned to winter and summer turned to autumn, and appeared between peaks of RSV and HMPV prevalence (Fig. 3).

\section{Correlation of RSV, PIV, and HMPV epidemics and meteorological conditions}

To explore the correlation of paramyxovirus prevalence with climate conditions in Guangzhou, we collected meteorological data for the 7-year period. Between July 2009 and June 2016, the mean temperature was $21.8 \pm 5.8{ }^{\circ} \mathrm{C}$, mean relative humidity was $77.2 \pm 7.3 \%$, sunshine duration was $132.7 \pm 59.5 \mathrm{~h}$, mean wind speed was $2.2 \pm 0.6 \mathrm{~m} / \mathrm{s}$, rainfall was $175.2 \pm 165.9 \mathrm{~mm}$, mean air pressure was $1005.6 \pm$ $6.0 \mathrm{hPa}$, and mean vapor pressure was $21.3 \pm 7.4 \mathrm{hPa}$.

Multiple linear regression analysis was conducted to explore the correlation between meteorological conditions and paramyxovirus prevalence. We first analyzed linear correlations among meteorological independent variables. We excluded the independent variables mean air pressure (adjusted $R^{2}=0.793, p<0.001$ ) and mean vapor pressure (adjusted $R^{2}=0.929, p<0.001$ ), which were linearly associated with mean temperature, and we excluded rainfall (adjusted $R^{2}=$ $0.278, p<0.001$ ), which was strongly correlated with mean relative humidity. Thus, the independent variables included in the final multiple linear regression analysis were mean temperature, mean relative humidity, sunshine duration, and mean wind speed. Multiple linear regression models were 
Table 1 Respiratory pathogens detected among hospitalized pediatric patients with acute respiratory illness: Guangzhou, Southern China

\begin{tabular}{|c|c|c|c|c|c|c|c|c|c|c|c|c|c|c|c|c|}
\hline \multirow[t]{2}{*}{ Pathogens } & \multicolumn{15}{|c|}{ No. of positive samples with potential pathogens } & \multirow[t]{2}{*}{ Prevalence, $\%(\mathrm{n}=11,398)$} \\
\hline & RSV & PIV & HMPV & $\operatorname{infA}$ & $\operatorname{infB}$ & $\mathrm{HRV}^{\mathrm{a}}$ & EV & $229 \mathrm{E}$ & OC43 & NL63 & HKU1 & $\mathrm{ADV}$ & $\mathrm{HBoV}$ & MP & $\mathrm{CP}$ & \\
\hline RSV & 1690 & 38 & 16 & 95 & 25 & 45 & 73 & 10 & 29 & 10 & 3 & 38 & 29 & 38 & 8 & 14.8 \\
\hline PIV & & 502 & 7 & 25 & 8 & 18 & 29 & 5 & 28 & 2 & 1 & 17 & 18 & 36 & 1 & 4.4 \\
\hline HMPV & & & 321 & 12 & 5 & 3 & 10 & 3 & 14 & 1 & 1 & 9 & 7 & 9 & 0 & 2.8 \\
\hline $\operatorname{infA}$ & & & & 839 & 34 & 8 & 41 & 7 & 38 & 4 & 4 & 23 & 13 & 46 & 1 & 7.4 \\
\hline $\operatorname{infB}$ & & & & & 300 & 6 & 9 & 0 & 9 & 0 & 1 & 4 & 4 & 15 & 2 & 2.6 \\
\hline $\mathrm{HRV}^{\mathrm{a}}$ & & & & & & 402 & 16 & 2 & 11 & 1 & 1 & 14 & 17 & 21 & 6 & 5 \\
\hline EV & & & & & & & 498 & 4 & 10 & 6 & 1 & 24 & 15 & 21 & 5 & 4.4 \\
\hline $229 \mathrm{E}$ & & & & & & & & 64 & 14 & 2 & 0 & 3 & 0 & 3 & 0 & 0.6 \\
\hline OC43 & & & & & & & & & 346 & 2 & 1 & 14 & 9 & 27 & 3 & 3.0 \\
\hline NL63 & & & & & & & & & & 60 & 1 & 5 & 3 & 3 & 1 & 0.5 \\
\hline HKU1 & & & & & & & & & & & 38 & 2 & 1 & 3 & 1 & 0.3 \\
\hline ADV & & & & & & & & & & & & 621 & 14 & 36 & 0 & 5.4 \\
\hline $\mathrm{HBoV}$ & & & & & & & & & & & & & 248 & 14 & 0 & 2.2 \\
\hline MP & & & & & & & & & & & & & & 760 & 2 & 6.7 \\
\hline $\mathrm{CP}$ & & & & & & & & & & & & & & & 77 & 0.7 \\
\hline Single pathogen & 1314 & 318 & 243 & 546 & 203 & 261 & 286 & 26 & 185 & 28 & 19 & 458 & 136 & 531 & 51 & 40.4 \\
\hline Co-pathogens & 376 & 184 & 78 & 293 & 97 & 141 & 212 & 38 & 161 & 32 & 19 & 163 & 112 & 229 & 26 & 8.8 \\
\hline
\end{tabular}

${ }^{a}$ HRV detected since January 2012, and a total of 8084 cases were collected. 229E, human coronavirus 229E; OC43, human coronavirus OC43; NL63, human coronavirus NL63; HKU1, human coronavirus HKU1; MP, Mycoplasma pneumoniae; CP, Chlamydophila pneumoniae

established for RSV, PIV, and HMPV prevalence and meteorological data $(p<0.05)$ (Table 2$)$.

RSV prevalence was negatively correlated with relative humidity and sunshine duration (coefficient $=-0.573$ and 0.097 , respectively) $(p<0.05)$. PIV prevalence was negatively correlated with relative humidity (coefficient $=-0.194)$ and positively correlated with temperature (coefficient $=$ $0.328)(p<0.05)$. HMPV prevalence was negatively correlated with sunshine duration (coefficient $=-0.024)(p<0.05)$ (Table 2, Fig. 4). Mean temperature drop 1 month (mean temperature in the preceding month) was also included as an independent variable in the analysis; however, no effective regression model was established $(p>0.05)$.

\section{Discussion}

ARI is one of the most common human diseases resulting in high mortality and mobility, and it is predominantly caused by respiratory viruses [31, 32]. Paramyxoviruses, including RSV, PIV, and HMPV, are the most important respiratory viruses in patients with ARI all over the world, especially among
Fig. 1 Respiratory pathogen distribution among hospitalized pediatric patients with acute respiratory illness in Guangzhou, China

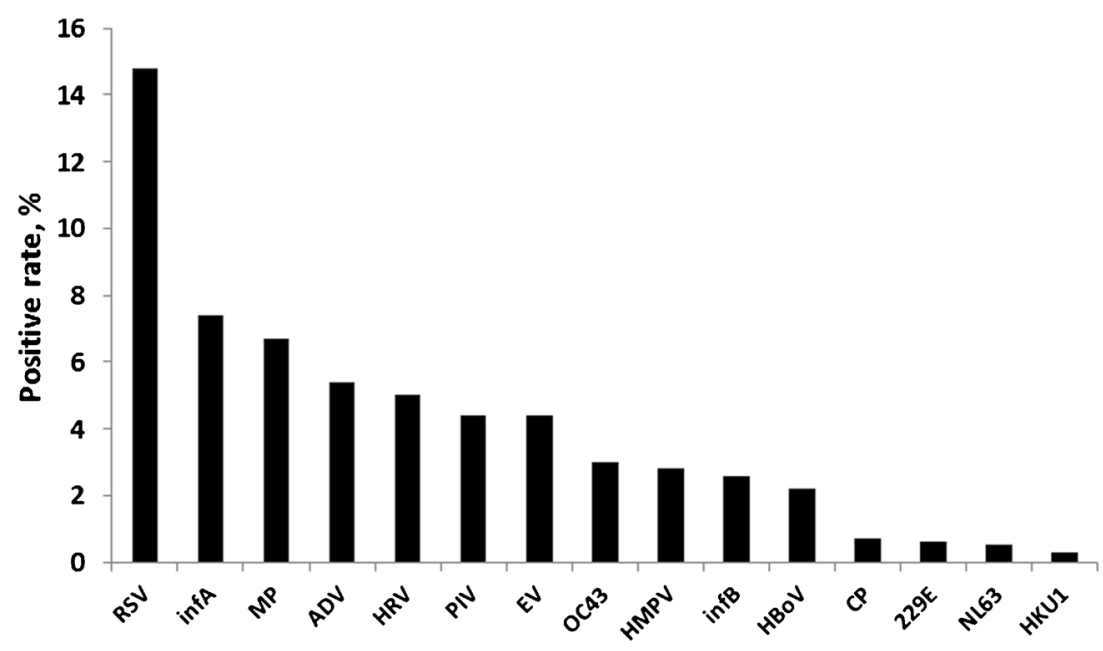




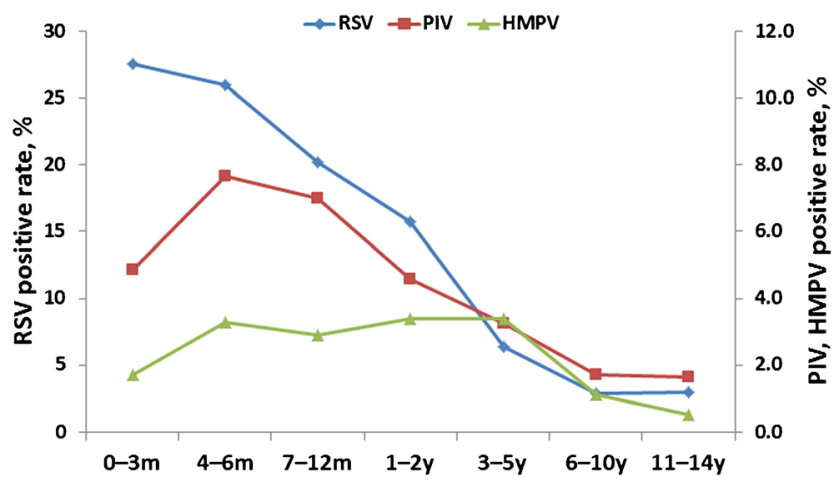

Fig. 2 Age distribution of RSV, PIV, and HMPV among hospitalized patients with acute respiratory illness, Guangzhou

children under 5 years old $[33,34]$. These viruses are also an important cause of nosocomial infection [18-25]. Currently, no effective vaccines or drugs have been developed against these viruses, except palivizumab for RSV prophylaxis [18].
Thus, additional research must be carried out. In the present study, we sought to analyze the features of paramyxovirus infection and correlation with meteorological conditions in a subtropical region of southern China, by collecting respiratory samples from pediatric patients $(\leq 14$ years old) hospitalized with ARI in Guangzhou and testing for RSV, PIV, HMPV, and other common respiratory pathogens. Meteorological data were also collected between July 2009 and June 2016, for further correlation analysis. The goal of the study was to reveal information that could be useful in the prevention and control of these viruses.

The median age of the 11,398 enrolled pediatric patients was 1.8 years (IQR, 0.8-3.8), indicating the high public health burden among infants and young children, as previously reported $[33,34]$. Nearly half of all patients had positive test results for one or more of the pathogens of interest; moreover, all pathogens in the panel were detected, indicating the complexity and diversity of ARI etiology (Table 1).
Fig. 3 Seasonal distribution of RSV, PIV, HMPV in hospitalized pediatric patients with acute respiratory illness, Guangzhou

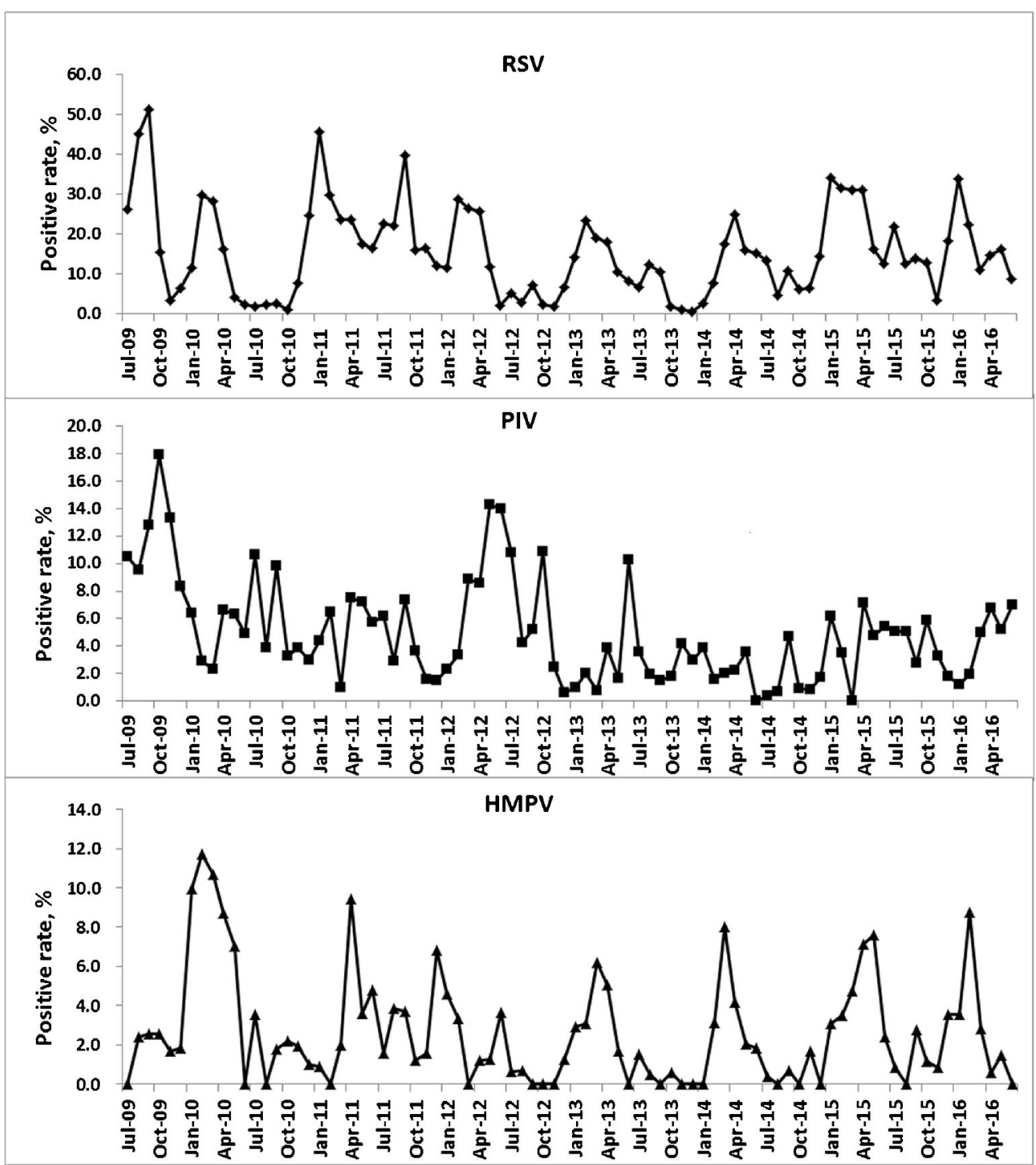


Table 2 Multiple linear regression analysis of correlation between RSV, PIV, HMPV epidemics and meteorological factors, Guangzhou

\begin{tabular}{|c|c|c|c|c|c|}
\hline \multirow[t]{2}{*}{ Pathogen } & \multicolumn{2}{|l|}{ Model summary } & \multicolumn{3}{|l|}{ Correlation coefficients } \\
\hline & Model significance (ANOVA) & Adjusted $R^{2}$ & Meteorological factor & Standard coefficient & $p$ value \\
\hline \multirow[t]{4}{*}{ RSV } & \multirow[t]{4}{*}{$p=0.048$} & \multirow[t]{4}{*}{0.069} & Mean temperature $\left({ }^{\circ} \mathrm{C}\right)$ & 0.59 & 0.14 \\
\hline & & & Mean relative humidity $(\%)$ & -0.573 & 0.034 \\
\hline & & & Mean wind speed (m/s) & 4.005 & 0.144 \\
\hline & & & Sunshine duration (h) & -0.097 & 0.007 \\
\hline \multirow[t]{4}{*}{ PIV } & \multirow[t]{4}{*}{$p<0.001$} & \multirow[t]{4}{*}{0.197} & Mean temperature $\left({ }^{\circ} \mathrm{C}\right)$ & 0.328 & 0.009 \\
\hline & & & Mean relative humidity $(\%)$ & -0.194 & 0.02 \\
\hline & & & Mean wind speed (m/s) & -0.699 & 0.404 \\
\hline & & & Sunshine duration (h) & -0.2 & 0.246 \\
\hline \multirow[t]{4}{*}{ HMPV } & \multirow[t]{4}{*}{$p<0.001$} & \multirow[t]{4}{*}{0.188} & Mean temperature $\left({ }^{\circ} \mathrm{C}\right)$ & -0.016 & 0.863 \\
\hline & & & Mean relative humidity $(\%)$ & -0.057 & 0.357 \\
\hline & & & Mean wind speed (m/s) & -0.81 & 0.2 \\
\hline & & & Sunshine duration (h) & -0.024 & 0.004 \\
\hline
\end{tabular}

Multiple linear regression analysis was performed for monthly prevalence of three paramyxoviruses as the dependent variable, and monthly mean temperature, mean relative humidity, sunshine duration, and mean wind speed as the independent variables

Data in italics are significant

Higher pathogen prevalence was found among male patients than female ones $(p=0.002)$, similar to previous reports [35]. RSV, infA, MP, ADV, HRV, and PIV were the six most frequently detected pathogens in this study (Fig. 1); these results are consistent with previous reports from China as well as international studies [1, 2, 35, 36].

RSV, PIV, and HMPV are the most important respiratory viruses, causing lower respiratory illnesses among children worldwide [4-6, 33]. In this study, RSV, PIV, and HMPV were the first $(14.8 \%)$, sixth $(4.4 \%)$, and ninth $(2.8 \%)$ most frequently detected pathogens (Table 1, Fig. 1). In children with positive results for these three paramyxoviruses, the median age was highest in children who were HMPV positive and lowest for those positive for RSV. RSV mostly affected children under 2 years old, and the prevalence decreased with age $(p<0.001)$. PIV showed peak prevalence among patients aged 4-6 months $(p<0.001)$, and there was high HMPV prevalence among patients aged 4 months to 5 years $(p<0.001)$ (Fig. 2). The different age distributions of these three viruses may be helpful in determining appropriate pediatric care and disease diagnosis; however, laboratory testing is still necessary because of the complex diversity and similarities in clinical manifestations of respiratory pathogens [1, 2, 4].

In general, the epidemiology of the main respiratory viruses in patients with ARI has been closely monitored in developed countries; however, these data are less available in developing countries, mostly because of the high cost of these studies. RSV is known to occur in well-defined, recurrent epidemics during the cold season in temperate climates [6], with peaks occurring more often during the rainy season in tropical and subtropical areas; locations close to the equator have less consistent patterns, with some showing nearly continuous RSV activity and varying seasonal peaks [37]. In this study, we found that RSV occurred during the change of seasons from winter to spring and from summer to autumn. This pattern is similar to those in previous reports [38]. HMPV had a similar epidemic pattern to RSV, consistent with previous reports from other subtropical areas [39, 40], and differed from the pattern in temperate climates, which peaks at the end of winter or in early spring [41, 42]. In previous reports from the USA, PIV is second only to RSV as a cause of hospitalization for ARI (2-17\%) among children aged younger than 5 years $[12,43,44]$. Seasonal peaks of PIV are mostly driven by PIV-3 and PIV-1, whereas there are a small number of PIV2 and especially PIV4 infections $[45,46]$. In this study, PIV was isolated throughout the year and appeared to alternate with peaks in RSV and HMPV infection, increasing as autumn turned to winter and summer turned to autumn (Fig. 3). These results differ from previous reports of biennial PIV epidemics $[45,47]$. The different geographic location might lead to the different seasonal distribution of PIV observed in the present study.

In addition to pathogenic characteristics, pathogenic epidemics are closely related to geographic environment, local climate, social development level, population structure, ethnic characteristics, social interaction, and so forth. Guangzhou has a maritime subtropical monsoon climate, with high temperatures (mean temperature $21.8 \pm 5.8^{\circ} \mathrm{C}$ ) and high relative humidity $(77.2 \pm 7.3 \%)$. Investigation of respiratory pathogen epidemics in the region is of great importance. In this study, we analyzed the correlation between the prevalence of paramyxoviruses among pediatric hospitalized patients and 


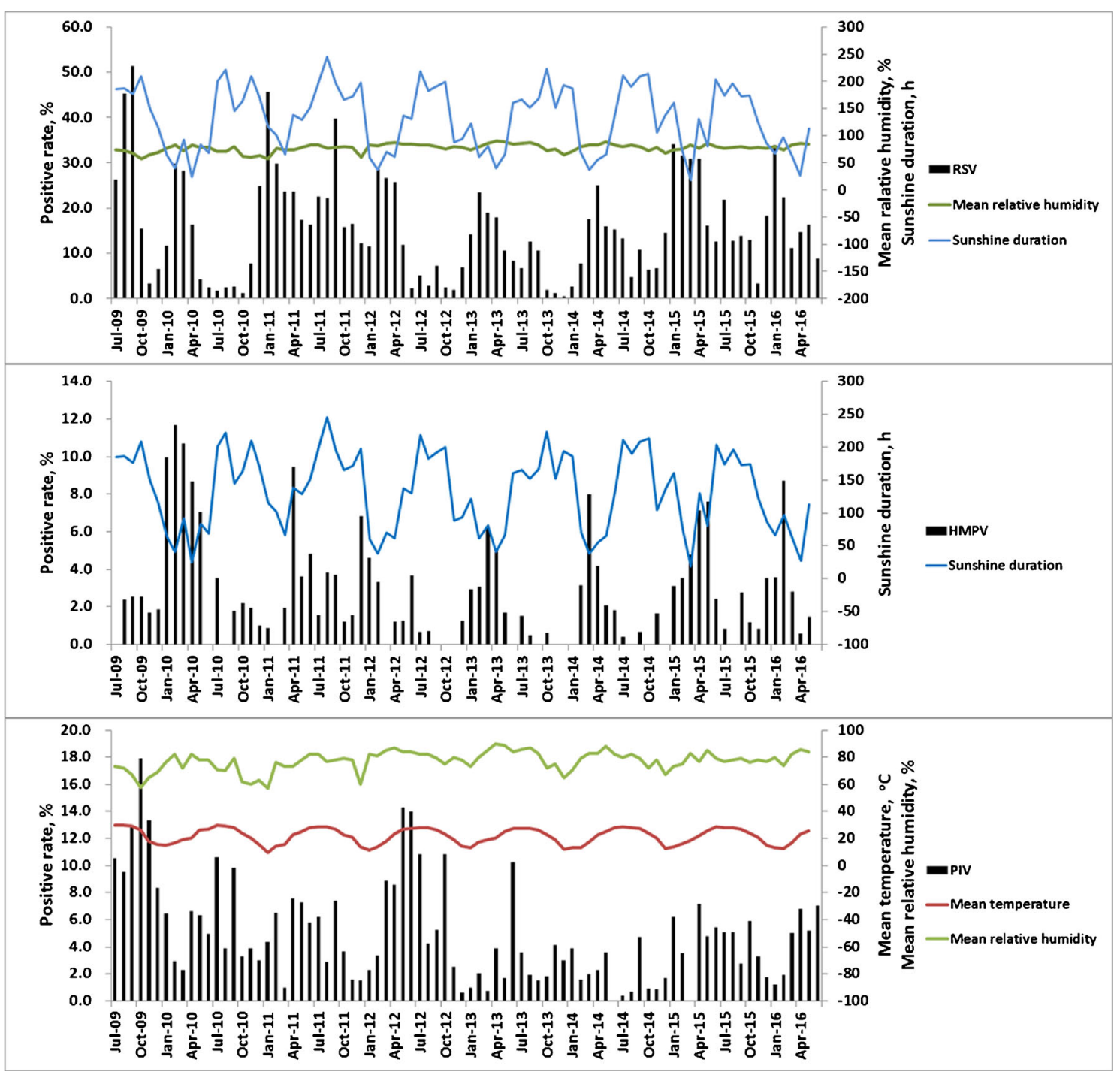

RSV prevalence was negativelycorrelated with relative humidityand sunshine duration $(p<0.05)$. PIV prevalence was negatively correlated with relative humidityand positivelycorrelated with temperature $(\mathrm{p}<0.05)$. HMPV prevalencewas negativelycorrelated withsunshine duration $(\mathrm{p}<0.05)$.

Fig. 4 Correlation of RSV, PIV, and HMPV prevalence with meteorological conditions in Guangzhou, China.

meteorological conditions in Guangzhou. Multiple linear regression analysis was performed with monthly RSV, PIV, and HMPV prevalence as the dependent variable and current mean temperature (or mean temperature in the preceding month), mean relative humidity, mean wind speed, and sunshine duration as the independent variables. Regression models were established for RSV, PIV, and HMPV using the current monthly temperature model $(p<0.05)$ (Table 2$)$. However, regression models using mean temperature in the preceding month model were not established. In general, the trend of associations between climate factors and respiratory pathogen activity varies with geographic location [35, 48-53]. In this study, RSV and HMPV had similar seasonal distribution patterns, and both were negatively correlated with sunshine duration
(Table 2, Fig. 4); this might be owing to the sensitivity of RSV and HMPV to ultraviolet light. In subtropical and temperate regions, RSV prevalence is more consistently positively correlated with lower temperatures and higher relative humidity [48]. However, we found a negative correlation between RSV prevalence and relative humidity $(p<0.05)$ (Table 2, Fig. 4), which might be owing to the high relative humidity in the Guangzhou region (monthly mean relative humidity $77.2 \pm 7.3 \%$ ). PIV had an alternating seasonal distribution pattern with RSV and HMPV in this study. PIV incidence was negatively correlated with relative humidity, similar to RSV; however, PIV incidence was positively correlated with mean temperature, and the absolute value of the correlation coefficient of relative humidity $(|-0.194|)$ was smaller 
than the absolute value of the correlation coefficient of temperature $(|0.328|)$ (Table 2), which means that the effect of temperature on the distribution of PIV was greater than the relative humidity. This might explain the different distribution patterns between RSV and PIV. Overall, the established models were found to be of value for understanding the epidemic patterns of RSV, PIV, and HMPV (Fig. 4).

Some limitations of this study should be noted. First, because our study was mainly focused on the circulation of paramyxoviruses among hospitalized patients with ARI, paramyxoviruses in outpatients and the asymptomatic population were not included. Second, many factors can affect virus epidemics; meteorological data analysis alone may be insufficient to reach a final conclusive interpretation. Third, the current study was only conducted in three hospitals and may not be representative of the overall population.

In conclusion, this study provided a better understanding of paramyxoviruses infection and highlighted the correlation with climate factors, revealing the potential for modeling and risk assessment. The findings of this work will help public health authorities and clinicians to improve strategies for controlling paramyxoviruses infection.

Acknowledgments We thank the study volunteers for their generous participation. We thank Huang-Xi Liang, Mei-Xin Chen, Chi Li, and Zhengshi Lin for their technical assistance.

Funding information This study was financially supported by the National Science and Technology Major Project of China (RZ, WKL) (2017ZX10103011003, 2018ZX10102001) (https://www.most.gov.cn); Guangzhou Science and Technology Program key projects (RZ) (201803040004, 201704020225) (http://www.gzsi.gov.cn); Science and Technology Planning Project of Guangdong Province of China (QL) (2016A020215001) (http://pro.gdstc.gov.cn); Natural Science Foundation of Guangdong Province of China (QL) (2018A030310401) (http://pro.gdstc.gov.cn); and National Natural Science Foundation of China (WKL) (31500143) (http://www.nsfc.gov.cn).

\section{Compliance with ethical standards}

Conflict of interest The authors declare that they have no conflicts of interest.

Ethical approval All procedures performed in studies involving human participants were in accordance with the ethical standards of The First Affiliated Hospital of Guangzhou Medical University Ethics Committee and with the 1964 Helsinki declaration and its later amendments or comparable ethical standards.

Informed consent This study is a retrospective study, and a formal consent is not required.

Open Access This article is distributed under the terms of the Creative Commons Attribution 4.0 International License (http:// creativecommons.org/licenses/by/4.0/), which permits unrestricted use, distribution, and reproduction in any medium, provided you give appropriate credit to the original author(s) and the source, provide a link to the Creative Commons license, and indicate if changes were made.

\section{References}

1. Ruuskanen O, Lahti E, Jennings L, Murdoch D (2011) Viral pneumonia. Lancet 377(9773):1264-1275. https://doi.org/10.1016/ S0140-6736(10)61459-6

2. Shi T, McLean K, Campbell H, Nair H (2015) Aetiological role of common respiratory viruses in acute lower respiratory infections in children under five years: a systematic review and meta-analysis. J Glob Health 5(1):010408. https://doi.org/10.7189/jogh.05.010408

3. Schuster JE, Williams JV (2014) Human metapneumovirus. Microbiol Spectr 2(5). https://doi.org/10.1128/microbiolspec.AID0020-2014

4. Tong AS, Hon KL, Tsang YC, Chan RW, Chan CC, Leung TF, Chan PK (2016) Paramyxovirus infection: mortality and morbidity in a pediatric intensive care unit. J Trop Pediatr 62(5):352-360. https://doi.org/10.1093/tropej/fmw016

5. Zhang L, Liu W, Liu D, Chen D, Tan W, Qiu S, Xu D, Li X, Liu T, Zhou R (2018) Epidemiological and clinical features of human metapneumovirus in hospitalised paediatric patients with acute respiratory illness: a cross-sectional study in southern China, from 2013 to 2016. BMJ Open 8(2):e019308. https://doi.org/10.1136/ bmjopen-2017-019308

6. Borchers AT, Chang C, Gershwin ME, Gershwin LJ (2013) Respiratory syncytial virus-a comprehensive review. Clin Rev Allergy Immunol 45(3):331-379. https://doi.org/10.1007/s12016013-8368-9

7. Schomacker H, Schaap-Nutt A, Collins PL, Schmidt AC (2012) Pathogenesis of acute respiratory illness caused by human parainfluenza viruses. Curr Opin Virol 2(3):294-299. https://doi. org/10.1016/j.coviro.2012.02.001

8. Pavia AT (2011) Viral infections of the lower respiratory tract: old viruses, new viruses, and the role of diagnosis. Clin Infect Dis 52(Suppl 4):S284-S289. https://doi.org/10.1093/cid/cir043

9. Papenburg J, Boivin G (2010) The distinguishing features of human metapneumovirus and respiratory syncytial virus. Rev Med Virol 20(4):245-260. https://doi.org/10.1002/rmv.651

10. Salimi V, Tavakoli-Yaraki M, Yavarian J, Bont L, Mokhtari-Azad T (2015) Prevalence of human respiratory syncytial virus circulating in Iran. J Infect Public Health. https://doi.org/10.1016/j.jiph.2015. 05.005

11. Hirsh S, Hindiyeh M, Kolet L, Regev L, Sherbany H, Yaary K, Mendelson E, Mandelboim M (2014) Epidemiological changes of respiratory syncytial virus (RSV) infections in Israel. PLoS One 9(3):e90515. https://doi.org/10.1371/journal.pone.0090515

12. Reed G, Jewett PH, Thompson J, Tollefson S, Wright PF (1997) Epidemiology and clinical impact of parainfluenza virus infections in otherwise healthy infants and young children $<5$ years old. J Infect Dis 175(4):807-813

13. Liu WK, Liu Q, Chen DH, Liang HX, Chen XK, Huang WB, Qin S, Yang ZF, Zhou R (2013) Epidemiology and clinical presentation of the four human parainfluenza virus types. BMC Infect Dis 13:28. https://doi.org/10.1186/1471-2334-13-28

14. van den Hoogen BG, de Jong JC, Groen J, Kuiken T, de Groot R, Fouchier RA, Osterhaus AD (2001) A newly discovered human pneumovirus isolated from young children with respiratory tract disease. Nat Med 7(6):719-724. https://doi.org/10.1038/89098

15. Boivin G, Abed Y, Pelletier G, Ruel L, Moisan D, Cote S, Peret TC, Erdman DD, Anderson LJ (2002) Virological features and clinical manifestations associated with human metapneumovirus: a new paramyxovirus responsible for acute respiratory-tract infections in all age groups. J Infect Dis 186(9):1330-1334. https://doi.org/10. $1086 / 344319$

16. Falsey AR, Walsh EE (2006) Viral pneumonia in older adults. Clin Infect Dis 42(4):518-524. https://doi.org/10.1086/499955 
17. Kahn JS (2006) Epidemiology of human metapneumovirus. Clin Microbiol Rev 19(3):546-557. https://doi.org/10.1128/CMR. 00014-06

18. Ashkenazi-Hoffnung L, Dotan M, Livni G, Amir J, Bilavsky E (2014) Nosocomial respiratory syncytial virus infections in the palivizumab-prophylaxis era with implications regarding high-risk infants. Am J Infect Control 42(9):991-995. https://doi.org/10. 1016/j.ajic.2014.05.030

19. Thorburn K, Eisenhut M, Riordan A (2012) Mortality and morbidity of nosocomial respiratory syncytial virus (RSV) infection in ventilated children-a ten year perspective. Minerva Anestesiol 78(7):782

20. Chu HY, Englund JA, Podczervinski S, Kuypers J, Campbell AP, Boeckh M, Pergam SA, Casper C (2014) Nosocomial transmission of respiratory syncytial virus in an outpatient cancer center. Biol Blood Marrow Transplant 20(6):844-851. https://doi.org/10.1016/ j.bbmt.2014.02.024

21. Bont L (2009) Nosocomial RSV infection control and outbreak management. Paediatr Respir Rev 10(Suppl 1):16-17. https://doi. org/10.1016/S1526-0542(09)70008-9

22. March Rosello GA, Eiros Bouza JM (2014) Nosocomial respiratory viral infection. An Sist Sanit Navar 37(2):265-279

23. Lee AV, Bibby DF, Oakervee H, Rohatiner A, Ushiro-Lumb I, Clark DA, Mattes FM (2011) Nosocomial transmission of parainfluenza 3 virus in hematological patients characterized by molecular epidemiology. Transpl Infect Dis 13(4):433-437. https://doi.org/10.1111/j.1399-3062.2011.00603.x

24. Kim S, Sung H, Im HJ, Hong SJ, Kim MN (2009) Molecular epidemiological investigation of a nosocomial outbreak of human metapneumovirus infection in a pediatric hemato-oncology patient population. J Clin Microbiol 47(4):1221-1224. https://doi.org/10. 1128/JCM.01959-08

25. Cheng VC, Wu AK, Cheung CH, Lau SK, Woo PC, Chan KH, Li KS, Ip IK, Dunn EL, Lee RA, Yam LY, Yuen KY (2007) Outbreak of human metapneumovirus infection in psychiatric inpatients: implications for directly observed use of alcohol hand rub in prevention of nosocomial outbreaks. J Hosp Infect 67(4):336-343

26. (1998) Palivizumab, a humanized respiratory syncytial virus monoclonal antibody, reduces hospitalization from respiratory syncytial virus infection in high-risk infants. The IMpact-RSV Study Group. Pediatrics 102(3 Pt 1):531-537

27. Fenton C, Scott LJ, Plosker GL (2004) Palivizumab: a review of its use as prophylaxis for serious respiratory syncytial virus infection. Paediatr Drugs 6(3):177-197

28. De Halleux V, Lombet J, Rigo J (2007) Respiratory syncytial immunoprophylaxis with palivizumab. Rev Med Liege 62(5-6): 299-302

29. du Prel JB, Puppe W, Grondahl B, Knuf M, Weigl JA, Schaaff F, Schmitt HJ (2009) Are meteorological parameters associated with acute respiratory tract infections? Clin Infect Dis 49(6):861-868. https://doi.org/10.1086/605435

30. Liu WK, Chen DH, Liu Q, Liang HX, Yang ZF, Qin S, Zhou $R$ (2011) Detection of human bocavirus from children and adults with acute respiratory tract illness in Guangzhou, southern China. BMC Infect Dis 11:345. https://doi.org/10.1186/ 1471-2334-11-345

31. Walker CL, Rudan I, Liu L, Nair H, Theodoratou E, Bhutta ZA, O'Brien KL, Campbell H, Black RE (2013) Global burden of childhood pneumonia and diarrhoea. Lancet 381(9875):1405-1416. https://doi.org/10.1016/S0140-6736(13)60222-6

32. Luksic I, Kearns PK, Scott F, Rudan I, Campbell H, Nair H (2013) Viral etiology of hospitalized acute lower respiratory infections in children under 5 years of age - a systematic review and meta-analysis. Croat Med J 54(2):122-134
33. Fox JD (2007) Respiratory virus surveillance and outbreak investigation. J Clin Virol 40(Suppl 1):S24-S30. https://doi.org/10.1016/ S1386-6532(07)70006-9

34. Tregoning JS, Schwarze J (2010) Respiratory viral infections in infants: causes, clinical symptoms, virology, and immunology. Clin Microbiol Rev 23(1):74-98. https://doi.org/10.1128/CMR. 00032-09

35. Oliveira-Santos M, Santos JA, Soares J, Dias A, Quaresma M (2016) Influence of meteorological conditions on RSV infection in Portugal. Int J Biometeorol 60(12):1807-1817. https://doi.org/ 10.1007/s00484-016-1168-1

36. Wang TL, Chen ZM, Tang HF, Tang LF, Zou CC (2005) Viral etiology of pneumonia in children. Zhejiang Da Xue Xue Bao Yi Xue Ban 34(6):566-569 573

37. Weber MW, Mulholland EK, Greenwood BM (1998) Respiratory syncytial virus infection in tropical and developing countries. Tropical Med Int Health 3(4):268-280

38. Mathisen M, Strand TA, Sharma BN, Chandyo RK, ValentinerBranth P, Basnet S, Adhikari RK, Hvidsten D, Shrestha PS, Sommerfelt H (2009) RNA viruses in community-acquired childhood pneumonia in semi-urban Nepal; a cross-sectional study. BMC Med 7:35. https://doi.org/10.1186/1741-7015-7-35

39. Garcia-Garcia ML, Calvo C, Rey C, Diaz B, Molinero MD, Pozo F, Casas I (2017) Human metapnuemovirus infections in hospitalized children and comparison with other respiratory viruses. 2005-2014 prospective study. PloS one 12(3):e0173504. https://doi.org/10. 1371/journal.pone. 0173504

40. Peiris JS, Tang WH, Chan KH, Khong PL, Guan Y, Lau YL, Chiu SS (2003) Children with respiratory disease associated with metapneumovirus in Hong Kong. Emerg Infect Dis 9(6):628-633. https://doi.org/10.3201/eid0906.030009

41. Maggi F, Pifferi M, Vatteroni M, Fornai C, Tempestini E, Anzilotti S, Lanini L, Andreoli E, Ragazzo V, Pistello M, Specter S, Bendinelli M (2003) Human metapneumovirus associated with respiratory tract infections in a 3-year study of nasal swabs from infants in Italy. J Clin Microbiol 41(7):2987-2991

42. van den Hoogen BG, van Doornum GJ, Fockens JC, Cornelissen JJ, Beyer WE, de Groot R, Osterhaus AD, Fouchier RA (2003) Prevalence and clinical symptoms of human metapneumovirus infection in hospitalized patients. J Infect Dis 188(10):1571-1577. https://doi.org/10.1086/379200

43. Iwane MK, Edwards KM, Szilagyi PG, Walker FJ, Griffin MR, Weinberg GA, Coulen C, Poehling KA, Shone LP, Balter S, Hall CB, Erdman DD, Wooten K, Schwartz B (2004) Population-based surveillance for hospitalizations associated with respiratory syncytial virus, influenza virus, and parainfluenza viruses among young children. Pediatrics 113(6):1758-1764

44. Shay DK, Holman RC, Newman RD, Liu LL, Stout JW, Anderson LJ (1999) Bronchiolitis-associated hospitalizations among US children, 1980-1996. JAMA 282(15):1440-1446

45. Fry AM, Curns AT, Harbour K, Hutwagner L, Holman RC, Anderson LJ (2006) Seasonal trends of human parainfluenza viral infections: United States, 1990-2004. Clin Infect Dis 43(8):10161022

46. Gardner SD (1969) The isolation of parainfluenza 4 subtypes A and $\mathrm{B}$ in England and serological studies of their prevalence. J Hyg (Lond) 67(3):545-550

47. Murphy B, Phelan PD, Jack I, Uren E (1980) Seasonal pattern in childhood viral lower respiratory tract infections in Melbourne. Med J Aust 1(1):22-24

48. Tang JW, Loh TP (2014) Correlations between climate factors and incidence-a contributor to RSV seasonality. Rev Med Virol 24(1): 15-34. https://doi.org/10.1002/rmv.1771

49. Lapena S, Robles MB, Castanon L, Martinez JP, Reguero S, Alonso MP, Fernandez I (2005) Climatic factors and lower respiratory tract 
infection due to respiratory syncytial virus in hospitalised infants in northern Spain. Eur J Epidemiol 20(3):271-276

50. Sundell N, Andersson LM, Brittain-Long R, Lindh M, Westin J (2016) A four year seasonal survey of the relationship between outdoor climate and epidemiology of viral respiratory tract infections in a temperate climate. J Clin Virol 84:59-63

51. Wang Y, Chen Z, Yan YD, Guo H, Chu C, Liu J, Ding Y, Shao X, Xu J, Ji W (2013) Seasonal distribution and epidemiological characteristics of human metapneumovirus infections in pediatric inpatients in Southeast China. Arch Virol 158(2):417-424. https://doi. org/10.1007/s00705-012-1492-7
52. Sung RY, Murray HG, Chan RC, Davies DP, French GL (1987) Seasonal patterns of respiratory syncytial virus infection in Hong Kong: a preliminary report. J Infect Dis 156(3):527-528

53. Tang JW, Lai FY, Wong F, Hon KL (2010) Incidence of common respiratory viral infections related to climate factors in hospitalized children in Hong Kong. Epidemiol Infect 138(2):226-235. https:// doi.org/10.1017/S0950268809990410

Publisher's note Springer Nature remains neutral with regard to jurisdictional claims in published maps and institutional affiliations.

\section{Affiliations}

\section{Wen-Kuan Liu ${ }^{1}$ - De-Hui Chen ${ }^{2} \cdot$ Wei-Ping Tan ${ }^{3} \cdot$ Shu-Yan Qiu ${ }^{1} \cdot$ Duo Xu ${ }^{1} \cdot$ Li Zhang $^{1} \cdot$ Shu-Jun Gu ${ }^{2} \cdot$ Rong Zhou $^{1}$ • Qian Liu ${ }^{4,5}$}

1 State Key Laboratory of Respiratory Diseases, National Clinical Research Center for Respiratory Disease, The First Affiliated Hospital of Guangzhou Medical University, Guangzhou Institute of Respiratory Health, Guangzhou Medical University, Guangzhou, China

2 Department of Pediatrics, The First Affiliated Hospital of Guangzhou Medical University, Guangzhou, China
3 Department of Pediatrics, Sun Yat-Sen Memorial Hospital, Sun YatSen University, Guangzhou, China

4 Scientific Research Center, The First Affiliated Hospital of Guangdong Pharmaceutical University, Guangzhou, China

5 Department of Pediatrics, Dongguan Eighth People's Hospital, Dongguan, China 